\title{
PATENT DUCTUS ARTERIOSUS WITH PULMONARY HYPERTENSION
}

\author{
BY \\ PETER HARRIS * \\ From the Cardiological Department, King's College Hospital \\ Received August 23, 1954
}

For many years there have been occasional reports of patients with persistent patent ductus arteriosus who have not had the usual Gibson murmur and who at necropsy have been found to have thickening of the small pulmonary arteries and right ventricular hypertrophy (Holman, 1925; Apert and Baillet, 1932; Keys and Shapiro, 1943; Chapman and Robbins, 1944; Douglas et al., 1947; Ulrich, 1947). With the aid of cardiac catheterization, it is now possible to diagnose such atypical cases during life, and during recent years many of these patients have been described (Dushane and Montgomery, 1948; Bouchard et al., 1950; Johnson et al., 1950; Mannheimer, 1950; Novelo et al., 1950; Pritchard et al., 1950; Campbell and Hudson, 1951; Myers et al., 1951; Adams et al., 1952; Cosh, 1953; Dammann et al., 1953; Hultgren et al., 1953). The feature common to all these patients is the presence of a raised pressure in the pulmonary artery giving rise to right ventricular hypertrophy. The pressure in the pulmonary artery may in fact exceed that in the aorta, in which case there is a reversal of flow along the ductus with consequent cyanosis.

The following is an account of a patient with patent ductus arteriosus and pulmonary hypertension in whom the information as to natural history, physiology and morbid anatomy seems to be unusually complete.

\section{Case Report}

The patient, a housewife of 43, was first seen in December, 1952. Since the preceding summer she had had four attacks of rapid, irregular beating of the heart each lasting several hours, and there had been increasing shortness of breath on exertion. The heart had been found to be abnormal at the age of eight, but there had been no disability before her forty-third year. She had had normal pregnancies and deliveries at 25 and 29 years of age.

There was no cyanosis or clubbing and no evidence of heart failure. The pulse was regular and of a collapsing nature with excessive pulsation visible in the carotids. The apex beat was in the anterior axillary line in the sixth intercostal space and the thrust of a hypertrophied right ventricle could be felt just to the left of the sternum. There was a remarkably strong diastolic thrill in the second and third spaces to the left of the sternum. This was associated with an intense diastolic murmur loudest in this area, but audible over the entire præcardium. It occupied the whole of diastole and was of a very coarse character, seeming to the ear to include vibrations of a lower pitch than are heard in the usual murmur of regurgitation from pulmonary artery or aorta. The timing of the murmur was confirmed later by phonocardiography (Fig. 1). There was no murmur in sytole.

Skiagrams and cardioscopy showed some enlargement of each ventricle and considerable dilatation of the trunk of the pulmonary artery and of its two main branches; in these an excessive intrinsic pulsation was visible (Fig. 2). The aorta also was thought to be a little large. A cardiogram was interpreted as showing evidence of hypertrophy of both ventricles.

Two weeks later she was admitted urgently to hospital with congestive heart failure and auricular fibrillation. The venous pressure was $26 \mathrm{~cm}$. water, rising to $30 \mathrm{~cm}$. on pressing over the liver. She was

\footnotetext{
* Wiltshire Memorial Research Scholar.
} 
E.C.G.

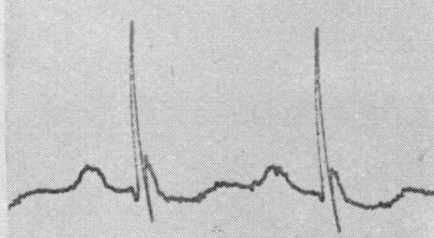

PHONO.

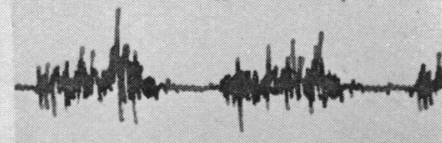

PULMONARY ARTERY PRESSURE
PHONO.
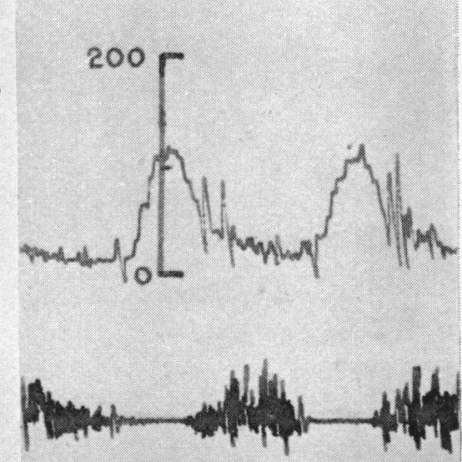

FIG. 1.-Phonocardiogram, with simultaneous electrocardiogram and pulmonary artery pressure tracing, to show the diastolic timing of the murmur.

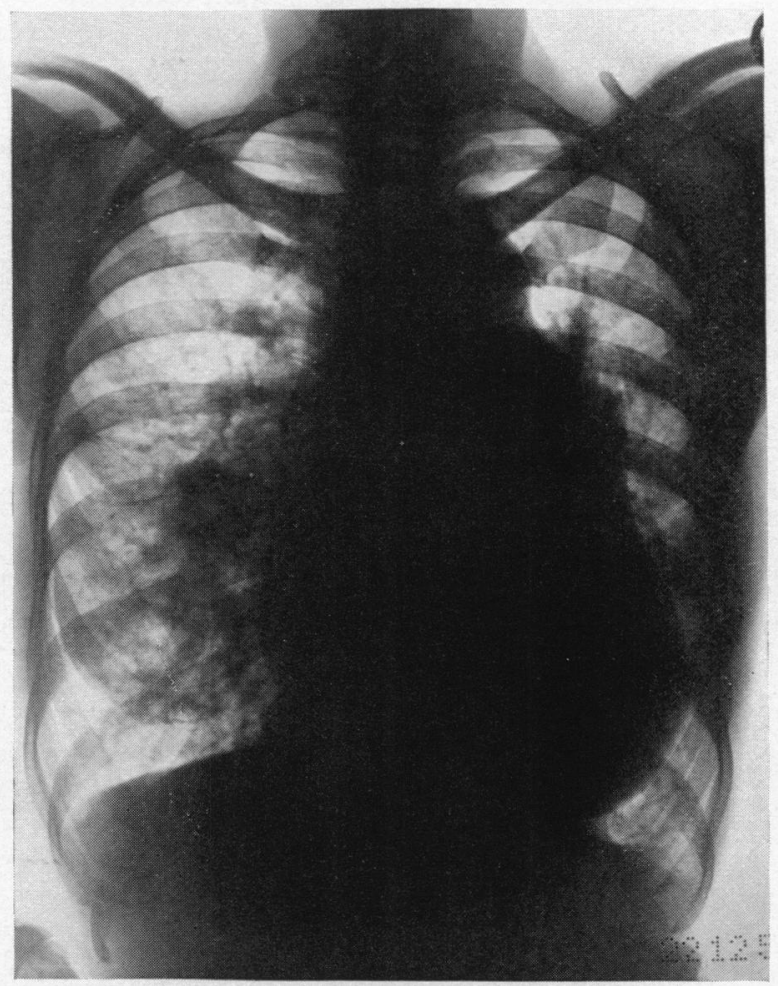

Fig. 2.-Postero-anterior view of the heart.

treated with rest, digitalis, a diet poor in salt, and injections of mersalyl. Within six weeks she was well again and the heart in normal rhythm.

Cardiac catheterization was carried out at that time. The oxygen content of the blood in the pulmonary artery $(88 \%)$ was found to be very much higher than that in the right ventricle $(73 \%)$, signifying a shunt from the aorta into the pulmonary artery. In addition, the sample from the inflow tract of the right ventricle was more highly oxygenated than that from the atrium $(66 \%)$. This difference of 
1.3 vols. per cent is probably significant (Holling and Zak, 1950) and was thought to indicate pulmonary incompetence.

The pressure recordings showed a high " $a$ " wave in the right atrium. The systolic pressure in the pulmonary artery $(140 / 10)$ was much higher than normal, but the diastolic pressure was within the normal range. The pulse pressure was therefore wide and this would bear out the presence of severe pulmonary incompetence. The mean pulmonary artery pressure was high $(55 \mathrm{~mm}$.).

The systolic pressure in the pulmonary artery (140/10) was found to equal the systolic pressure in the femoral artery (140/20). Although these records were not simultaneous and although the curve of pressure in the femoral artery may not correspond exactly with that in the aorta (Hamilton and Dow, 1939) it was thought that the similarity of these two pressures might help to explain the physical signs, for no murmur could be heard in systole and it seemed reasonable to conclude that the gradient of pressure between aorta and pulmonary artery was insufficient to cause a flow along the ductus during this part of the cycle. The similarity in oxygen content of samples of blood taken from the right brachial ( $96 \%$ ) and left femoral arteries $(97 \%)$ ruled out the presence of a significant right-to-left shunt through the ductus.

An angiocardiogram showed the very great dilatation of the pulmonary artery trunk and its main divisions, while the peripheral branches appeared normal. There was no visible flow of dye from pulmonary artery to aorta.

Shortly after these investigations had been carried out, it was learned that she had been a patient at the Hospital for Sick Children at the age of nine and in the Middlesex Hospital during her first pregnancy when she was 25 . These hospitals have kindly sent details of their findings. At the age of nine she was noted to have a systolic murmur in the pulmonary area and a loud pulmonary second sound. At the age of 25, when she was under Dr. G. E. S. Ward's care, the findings in the pulmonary area were noted as follows: " Thrill palpable throughout systole and diastole but mainly in diastole. Murmur of harsh character heard throughout systole and diastole. First sound audible. Second sound absent. Pulmonary pulsation palpable."

The diagnosis of a patent ductus arteriosus seemed therefore assured and an operation was advised, but the patient was unwilling to undergo this. She was allowed home at the end of February, 1953, but failure recurred, necessitating re-admission to hospital in June and again in August. At this time auricular fibrillation returned and the tricuspid valve became incompetent as judged by a sustained systolic venous pulse wave visible in the neck and palpable in the distended liver. She died in September of the same year, a little over a year after the onset of symptoms.

Necropsy showed a patent ductus arteriosus arising just beyond the origin of the left pulmonary artery (Fig. 3A). At this point the aorta abutted on the pulmonary artery and there was virtually no length to

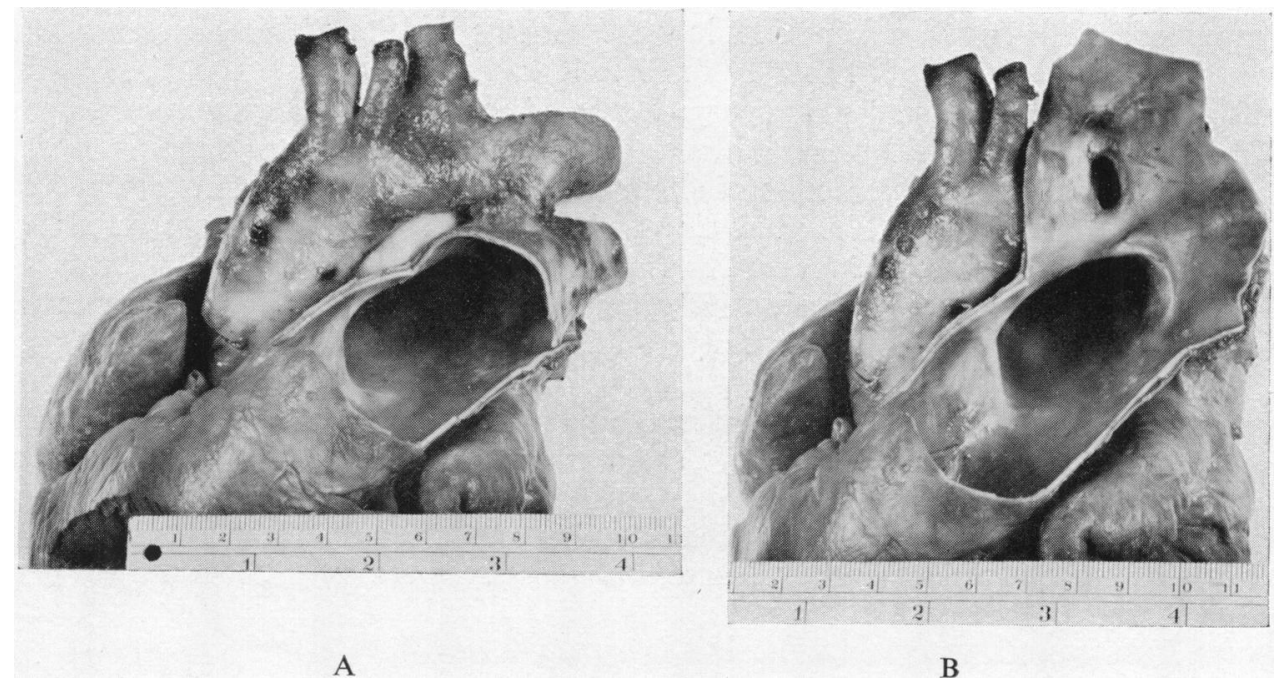

FIG. 3.-Frontal view of heart. (A) The anterior wall of the pulmonary artery has been partly cut away; the external appearance of the ductus is shown. (B) The anterior wall of the pulmonary artery has been reflected to show the internal appearance of the ductus. 

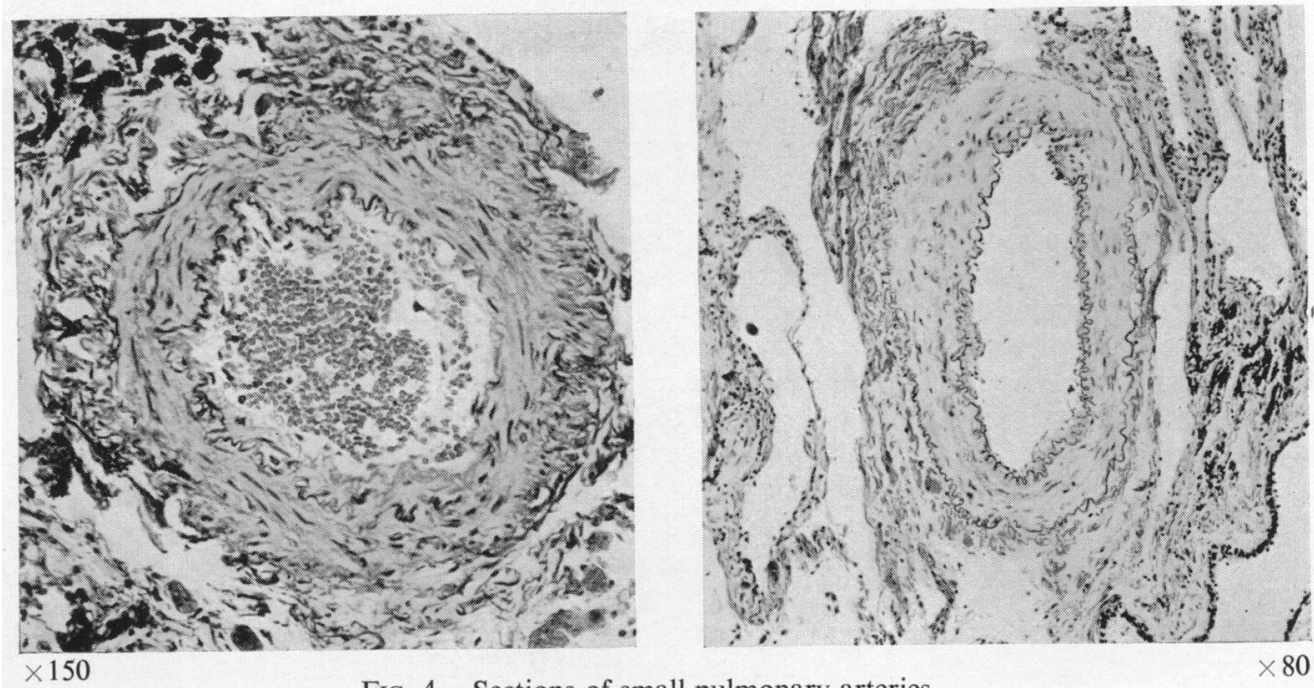

FIG. 4.- Sections of small pulmonary arteries.

the ductus. The pulmonary artery and two main branches were greatly dilated, the circumference of the main trunk being $12 \mathrm{~cm}$. The aorta was also dilated, with a circumference of $9 \mathrm{~cm}$. The internal diameter of the ductus was a little less than $1 \mathrm{~cm}$. (Fig. 3B). There was no " impingement plaque" in either vessel. Both ventricles were hypertrophied, the thickness of the right ventricular wall varying between 1 and $1.5 \mathrm{~cm}$., and that of the left ventricular wall between 1.5 and $2 \mathrm{~cm}$. The pulmonary valves were a little thickened and water flowed readily through them from the pulmonary artery into the right ventricle.

The lungs were dry, and the small pulmonary arteries appeared thickened and prominent on the cut surface. Under the microscope (Fig. 4) there was widespread thickening of the walls of the small muscular branches of the pulmonary artery. This could be seen to be due to a pronounced hypertrophy of the muscle of the media of these vessels. The adventitia showed an excess of fibrous tissue. There was also some proliferation of the intima of varying degrees in arterial branches of all sizes, but this was not outside the normal limits for the age.

\section{Discussion}

Why pulmonary hypertension is present in some patients who have a patent ductus arteriosus and not in the majority is not yet known. In some instances it has been thought to be due to a congenital abnormality of the small pulmonary arteries. In the fœtus, these vessels have a muscular media (Civin and Edwards, 1951) which is associated with a high resistance (Hamilton et al., 1937) and an abnormal persistance of this state of affairs might be the basis of pulmonary hypertension after birth (Civin and Edwards, 1950; Novelo et al., 1950; Campbell and Hudson, 1951; Cosh, 1953; Hultgren et al., 1953). To support this view is the fact that many of the patients reported are children; and, judging by the presence of cyanosis, a pressure in the pulmonary artery high enough to reverse the shunt often occurs early in life in these patients and may even be present at birth.

It is also possible that the high pressure in the pulmonary artery is acquired after birth. In only one previous instance, however, has a Gibson murmur been noted which subsequently disappeared, presumably with the onset of pulmonary hypertension. This is the patient reported by Campbell and Hudson (1952) who were of the opinion that the pulmonary hypertension was of acquired origin. In the patient described here, the high pressure in the pulmonary artery seems also to have developed later in life. For she is known to have had a Gibson murmur at 25 which was replaced by a purely diastolic murmur by the age of 43 .

If it be granted that the natural history of this patient's disease speaks against a congenital cause for the high pressure in her pulmonary artery, then it is hard to avoid the conclusion that a persistently increased flow of blood played some part in the initiation of this hypertension later in life. 
In considering how this might have come to pass, there are several diverse facts that have to be reconciled.

In the first place, exercise may cause a considerable increase in flow of blood through the lungs of a normal person with little or no rise in pressure (Hickam and Cargill, 1948; Riley et al., 1948; Cournand et al., 1950; Dexter et al., 1951). The pressure in the pulmonary artery is also usually normal in those abnormalities, such as patent ductus arteriosus or atrial or ventricular septal defects, which cause a persistently increased pulmonary blood flow. Yet it is in just these abnormalities that severe pulmonary hypertension is liable to occur. When this happens, the pulmonary "arteriolar" resistance is found to be higher than normal and it is this increased resistance and not any increase in flow which plays the important part in causing the pulmonary hypertension. Indeed, the rise in pressure in the pulmonary artery tends of itself to inhibit or even reverse the shunt of blood so that the flow through the lungs may actually be less than the systemic flow. In such patients the cyanosis may be observed to increase gradually in intensity. So that, beyond a certain stage, the pulmonary vascular resistance continues to rise despite the fact that the pulmonary blood flow is thereby progressively reduced below the systemic flow.

The estimation of pulmonary blood flow in this patient must be less accurate than usual owing to the presence of two distinct streams of blood in the pulmonary artery (Eppinger et al., 1941). The addition of severe pulmonary incompetence, however, may well offset this to a large extent by increasing the efficiency of mixing of these streams, and this is borne out by the similarity in oxygen content of the two samples taken from the pulmonary artery. Thus the indications are that the flow through the lungs was between three and four times that through the systemic circulation and that the pulmonary " arteriolar" resistance was also somewhat raised.

This increase in pulmonary "arteriolar" resistance can be correlated with the hypertrophy of muscle and the fibrosis found in the walls of the small pulmonary arteries. The same histological appearances have been described in similar patients by several authors, whatever view has been taken of the origin of the pulmonary hypertension (Douglas et al., 1947; Edwards et al., 1949; Swan et al., 1949; Johnson et al., 1950; Campbell and Hudson, 1951, 1952; Dammann et al., 1953; Cosh, 1953; Hultgren et al., 1953). In this patient, the preponderance of muscle over fibrous tissue in the walls of the small pulmonary arteries was confirmed pharmacologically during life by the action of acetylcholine. When this was injected through the catheter, it caused a great fall in pressure in the pulmonary artery which has not been observed in patients in whom this pressure is normal but which occurs in varying degree in the presence of pulmonary hypertension (Harris, 1953). Similar pharmacological studies have been reported by Halmgáyi et al. (1953).

The small pulmonary arteries of the normal lung are only meagerly provided with muscle (Brenner, 1935a; Parker and Weiss, 1936; Henry, 1952) and this is also usually the case in patients with patent ductus arteriosus (Welch and Kinney, 1948). Hypertrophy of the medial muscle in patent ductus seems in fact to be related to the presence of a high pressure in the pulmonary artery and not directly to increased flow. An excess of muscle tissue is universally the expression of an increased muscular work. Hypertrophy of the muscle of the media of a vessel must therefore imply active vasoconstriction occurring intermittently or continuously for a prolonged time. The effect of acetylcholine verifies the presence of such vasoconstriction in the pulmonary vessels of this patient.

Hypertrophy of the muscle of the media is not therefore the cause of arterial constriction but its effect. There is much muscle in the media of the small pulmonary arteries of the fotus. This is also found in the same arteries of patients with a patent ductus arteriosus and pulmonary hypertension. It cannot, however, be argued that a simple persistence of this muscle after birth would cause a high pressure in the pulmonary artery. What has to be postulated is a persistence of active vasoconstriction in these vessels which will maintain the bulk of the muscle. For it seems the universal rule that muscle tissue will atrophy when it ceases to be used.

In patients with mitral stenosis there is also a hypertrophy of the medial muscle in the small pulmonary arteries (Parker and Weiss, 1936; Larrabee et al., 1949; Henry, 1952) and this is accompanied by an increase in the resistance to flow specifically at the level of these vessels. Yet at no 
time in the evolution of this disease is there any abnormal increase in flow of blood through the lungs, but simply a generalized increase in intravascular pressure throughout them. The increase in pulmonary "arteriolar" resistance is diminished following valvotomy when the pressure falls throughout the lesser circulation (Draper et al., 1951; Carlotti et al., 1952; Lukas and Dotter, 1952). In mitral stenosis, therefore, the small pulmonary arteries appear to constrict and become muscular in response to a prolonged increase of pressure in the lesser circulation. On the other hand, a similar response has not been noted in normal people when the pressure has been artificially raised for a short period by infusing large volumes of fluid intravenously (Doyle et al., 1951; Witham et al., 1951). In the normal person, however, the medial muscle of these vessels is perhaps too scanty to be expected to cause any effective vasoconstriction in response to this particular stimulus, whereas a frequent repetition or continuation of the stimulus over a prolonged period might well cause the muscle to increase in bulk and thus in power.

The effects of exercise in patients with mitral stenosis suggest that this may be so, for Hickam and Cargill (1948) and Bayliss et al. (1950) found that occasionally there occurred a rise of pressure in the pulmonary artery far greater than could be explained by a fixed obstruction at the mitral valve. This is, however, by no means always the case (Draper et al., 1951; Gorlin et al., 1952; Lukas and Dotter, 1952).

How a rise in pressure in the pulmonary artery could provoke a constriction of its small branches is a matter for conjecture. The mechanism may be a nervous one, for afferent impulses have been demonstrated in the vagus which appear to arise from the pulmonary arterial tree and which are stimulated by each pulse wave (Walsh and Whitteridge, 1945; Whitteridge, 1948; Pearce and Whitteridge, 1951).

During cardiac catheterization in patients with many different types of lesion, the pulmonary artery pressure is often seen to vary considerably from moment to moment. This is particularly so when the patient is nervous and apprehensive. It might be expected that such fluctuations in the pulmonary artery pressure would more often bring it above the normal range in a patient with an increased flow of blood through the lungs than in a normal person, despite the fact that under basal conditions the pressure in the pulmonary artery is usually normal in such patients. It may be that this was the way in which constriction was at first stimulated in the small pulmonary arteries of the patient described here.

With these considerations in mind, the following sequence of events is put forward as a possible explanation of the development of pulmonary hypertension in some patients with a persistent patent ductus.

The increase in flow of blood through the lungs may of itself be high enough to cause some slight rise in pressure in the pulmonary artery. Or, more likely, the abnormal rise in pressure at first occurs only intermittently. Such a rise in pressure in some unknown way causes the small pulmonary arteries to constrict. The response of these vessels is at first very weak, as their medial muscle is small in bulk. Frequently repeated or continued vasoconstriction, however, eventually causes this muscle to hypertrophy. This in turn increases the power of constriction so that what was originally possibly a "vestigial " function (Dixon and Hoyle, 1928) becomes a very important activity. As the vasoconstriction increases in power, so the pressure in the pulmonary artery is raised still further and thus a vicious circle of hypertension and vasoconstriction is initiated. This vicious circle will continue despite the fact that the flow of blood through the pulmonary artery is progressively reduced. A further result of hypertension is the development in the small pulmonary arteries of intimal fibrosis (Civin and Edwards, 1950; Edwards and Chamberlin, 1951) which will still further increase their resistance. The laying down of fibrous tissue in the walls of these arteries may eventually impair their flexibility so that variations in calibre become mechanically more and more limited and the activity of the medial muscle, therefore, less and less important. By this time the damage is presumably permanent.

It still remains to explain why this condition occurs predominantly in children and young adults and often appears to have its origin in infancy. Perhaps the clue to this lies in the histological structure of the small pulmonary arteries in the first few months of life. Civin and Edwards 
(1951) have shown that the change from fœtal to post-natal structure in these vessels takes several months and during this time the media is excessively muscular. Hence at this time they are likely to be more responsive to the effects of high pressure in the manner outlined above, and the conditions are uniquely such as will foster the first stages of the vicious circle of hypertension and vasoconstriction.

There are several causes that might have initiated this vicious circle so much later in life in the patient described here. It is possible that the subintimal fibrosis which develops with advancing age and which is encouraged by an increased flow of blood (Welch and Kinney, 1948) may have had such an effect. The gradual development of a "window" type of ductus, as suggested by Dry et al. (1948), may have led to an increased shunt. Finally, the development of pulmonary incompetence by causing a high systolic pressure in the pulmonary artery may have evoked a repetitive constriction in the small branches.

\section{SUMMARY}

A patient with patent ductus arteriosus is described in whom the combination of pulmonary hypertension and pulmonary incompetence seemed to allow shunting of blood only in diastole. Because of this, the Gibson murmur which had been observed 18 years previously had given place to a murmur confined to diastole. The mechanisms whereby such a rise in pressure in the pulmonary artery might have arisen are discussed and it is suggested that small and intermittent elevations of pressure in the pulmonary artery may have eventually initiated a vicious circle of vasoconstriction and hypertension.

I am very grateful to Dr. Terence East for allowing me to study his patient and publish these results, and for suggesting the main lines of thought in the discussion of this paper. I am also indebted to Professor H. A. Magnus for his criticism and for advice on the morbid anatomical details.

\section{REFERENCES}

Adams, F. H., Diehl, A., Jorgens, J., and Veasey, L. G. (1952). J. Pediat., 40, 49.

Apert, E., and Baillet, P.-C. (1932). Arch. Med. Enf., 35, 147.

Bayliss, R. I. S., Etheridge, M. J., and Hyman, A. L. (1950). Lancet, 2, 889.

Bouchard, F., Lason, R. L., and Alvarez, V. R. (1950). ler Congrès Mondial. de Cardiologie, p. 271.

Brenner, O. (1935a). Arch. intern. Med., 56, 211.

- (1935b). Arch. intern. Med., 56, 457.

Campbell, M., and Hudson, R. (1951). Guy's Hosp. Rep., 100, 26.

(1952). Guy's Hosp. Rep., 101, 32.

Carlotti, H., Joly, F., Sicot, J.-R., Voci, G., and Cazals, F. (1952). Arch. Mal. Coeur, 45, 412.

Chapman, C., and Robbins, S. (1944). Ann. intern. Med., 21, 312.

Civin, W. H., and Edwards, J. E. (1950). Circulation (N.Y.), 2, 545. (1951). Arch. Path. Lab. Med., 51, 192.

Cosh, J. A. (1953). Brit. Heart J., 15, 423.

Cournand, A., Riley, R. L., Himmelstein, A., and Austrian, R. (1950). J. thorac. Surg., 19, 80.

Dammann, J. F., Berthrong, M., and Bing, R. J. (1953). Bull. Johns Hopk. Hosp., 92, 128.

Dexter, L., Whittenberger, J. L., Haynes, F. W., Goodale, W. T., Gorling, R., and Sawyer, C. G. (1951). J. appl. Physiol., 3, 439.

Dixon, W. E., and Hoyle, J. C. (1928). J. Physiol. (Lond.), 65, 299.

Douglas, J., Burchell, H., Edwards, J., Dry, T., and Parker, R. (1947). Proc. Mayo Clin., 22, 413.

Doyle, J. T., Wilson, J. S., Estes, E. H., and Warren, J. V. (1951). J. clin Invest., 30, 345.

Draper, A., Heimbecker, R., Daley, R., Carroll, D., Mudd, G., Wells, R., Falholt, W., Andrus, E. C., and Bing, R. J. (1951). Circulation (N.Y.), 3, 531 .

Dry, T. J., Harrington, S. W., and Edwards, J. E. (1948). Proc. Mayo Clin., 23, 267.

Dushane, J. W., and Montgomery, G. E. (1948). Proc. Mayo Clin., 23, 505.

Edwards, J. E., and Chamberlin, W. B. (1951). Circulation (N.Y.), 3, 524.

, Douglas, J. M., Burchall, H. B., and Christensen, N. A. (1949). Amer. Heart J., 38, 205.

Eppinger, E. C., Burwell, C. S., and Gross, R. E. (1941). J. clin. Invest., 20, 127.

Gorling, R., Sawyer, C. G., Haynes, F. W., Goodale, W. T., and Dexter, L. (1951). Amer Heart J., 41, 192.

Halmággi, D., Felkai, B., Iványi, J., Szótér, T., Tényi, M., and Szücs, Z. (1953). Brit. Heart J., 15, 15.

Hamilton, W. F., and Dow, P. (1939). Amer. J. Physiol., 125, 48.

-, Woodbury, R. A., and Woods, E. B. (1937). Amer. J. Physiol., 119, 206.

Harris, P. (1953). From observations not yet published.

Henry, E. W. (1952). Brit. Heart J., 14, 406. 
Hickam, J. B., and Cargill, W. H. (1948). J. clin. Invest., 27, 10.

Holling, H. E., and Zak, G. A. (1950). Brit. Heart J., 12, 153.

Holman, E. (1925). Bull. Johns Hopk. Hosp., 36, 61.

Hultgren, H., Selzer, A., Purdy, A., Holman, E., and Gerbode, F. (1953). Circulation (N.Y.), 8, 15.

Johnson, R., Werner, P., Kuschner, M., and Cournand, A. (1950). Circulation (N.Y.), 1, 1293.

Keys, A., and Shapiro, M. J. (1943). Amer. Heart J., 25, 159.

Larrabee, W. F., Parker, R. L., and Edwards, J. E. (1949). Proc. Mayo Clin., $24,316$.

Lukas, D. S., and Dotter, C. T. (1952). Amer. J. Med., 12, 639.

Mannheimer, E. (1950). Arch. Mal. Coeur, 43, 324.

Myers, G., Scannell, J., Wyman, S., Dinard, E., and Hurst, J. (1951). Amer. Heart J., 41, 819.

Novelo, S., Limon, R., and Bouchard, F. (1950). 1er Congrès Mondial de Cardiologie, p. 264.

Parker, F., Jr., and Weiss, S. (1936). Amer. J. Path., 12, 573.

Pearce, J. W., and Whitteridge, D. (1951). Quart. J. exp. Physiol., 36, 177.

Pritchard, W., Brofman, B., and Hellerstein, H. (1950). J. Lab. clin. Med., 36, 974.

Riley, R. L., Himmelstein, A., Motley, H. L., Weiner, H. M., and Cournand, A. (1948). Amer. J. Physiol., $152,372$.

Swan, H., Trapnell, J. M., and Denst, J. (1949). Amer. Heart J., 38, 914.

Ulrich, H. (1947). Acta med. scand., 196, 160.

Walsh, E. G., and Whitteridge, D. (1945). J. Physiol., 103, 370.

Welch, K. J., and Kinney, T. D. (1948). Amer. J. Path., 24, 729.

Whitteridge, D. (1948). J. Physiol., 107, 496.

Witham, A. C., Fleming, J. W., and Bloom, W. L. (1951). J. clin. Invest., 30, 897. 